\title{
Autosomal dominant intermediate Charcot-Marie-Tooth disease with neuropathic pain
}

INSERM

\section{Source}

INSERM. (1999). Orphanet: an online rare disease and orphan drug data base. Autosomal dominant intermediate Charcot-Marie-Tooth disease with neuropathic pain.

ORPHA:324585

Autosomal dominant intermediate Charcot-Marie-Tooth disease with neuropathic pain is a rare subtype of autosomal dominant intermediate Charcot-Marie-T ooth disease characterized by debilitating neuropathic pain associated with mild, distal, symmetrical lower limb sensory loss and mild or absent motor dysfunction. Patients typically manifest with burning, aching, shooting, or throbbing pain and intermittent paraesthesia in toes, heels and ankles. 